\title{
DERECHOS DE LAS PERSONAS CON DISCAPACIDAD HACIA LA INCLUSIÓN SOCIOLABORAL. VISIÓN ECUADOR Y VENEZUELA
}

\section{RIGHTS PEOPLE WITH DISABILITIES TOWARDS SOCIOLABORAL INCLUSION. VISION ECUADOR AND VENEZUELA}

\author{
Rosa Angélica Romero Chico ${ }^{1}$ \\ Dante Pino Pascucci Stelluto²
}

Recibido: 2019-01-08 / Revisado: 2019-03-02 / Aceptado: 2019-04-01 / Publicado: 2019-07-01

Forma sugerida de citar: Romero-Chico, R. A. y Pascucci-Stelluto, D. P. (2019). Derechos de las personas con discapacidad hacia la inclusión sociolaboral. Visión Ecuador y Venezuela. Retos de la Ciencia, 3(7), pp. 85-97. https://doi.org/10.53877/rc.3.7.20190701.08

\section{RESUMEN}

La revisión de las Constituciones de las repúblicas de Ecuador y Venezuela, Ley Orgánica de Discapacidades en Ecuador vigente a partir del 25 de septiembre del 2012 y Ley para las Personas con Discapacidad en Venezuela vigente a partir del 05 de enero de 2007, se desarrollan en base a un análisis comparativo de los derechos para personas con discapacidad hacia la inclusión sociolaboral. El objetivo de esta investigación es analizar, cuál es el tratamiento formal jurídico que impulsa las políticas públicas sobre las personas con discapacidad, en función de amparar, incluir, desarrollar una responsabilidad compartida entre el individuo, la familia, el trabajo, la sociedad y el Estado. Los métodos utilizados son analítico, deductivo y comparativo, la técnica la hermenéutica jurídica, para interpretar los textos. Se identifica la oportunidad de mejora en la determinación de los grados de discapacidad, la implementación controlada de las políticas públicas y que dichas políticas se basen en datos actualizados.

Palabras clave: inclusión, ley orgánica de discapacidad, derecho, política pública.

\section{ABSTRACT}

The revision of the Constitutions of the Republics of Ecuador and Venezuela, the Organic Law on Disabilities in Ecuador in force as of September 25, 2012 and the

\footnotetext{
${ }^{1}$ Magíster en Desarrollo Humano. Profesora de la Facultad de Psicología de la Universidad Central del Ecuador. Ecuador. E-mail: raromeroch@uce.edu.ec

${ }^{2}$ Ph.D en Gerencia Avanzada. Profesor titular e Investigador de la Universidad de Los Andes. Venezuela. Email: dante@ula.ve
} 
Law for Persons with Disabilities in Venezuela in force as of January 5, 2007, are developed based on a comparative analysis of the rights of persons with disabilities. The objective of this research is to analyze what is the formal legal treatment that promotes public policies on people with disabilities, in order to protect, include, and develop a shared responsibility between the individual, the family, the work, society and the State. The methods used are deductive and comparative; the technique is legal hermeneutics, to interpret the texts. The opportunity is identified for improvement in the determination of the degrees of disability, the controlled implementation of public policies and that these policies are based on updated data.

Keywords: inclusion, disability law, law, public policy.

\section{INTRODUCCIÓN}

El objeto de estudio del artículo es el estado de los derechos de las personas con discapacidad para la inclusión sociolaboral en Ecuador y Venezuela. La revisión inicia con la definición del concepto discapacidad, persona con discapacidad e inclusión vista desde la persona y desde los otros ciudadanos: Primero, discapacidad es una condición de salud, biológica y/o social, que limita una o más funciones de forma permanente y comprobable. Segundo, personas con discapacidad son aquellos seres humanos que poseen deficiencias biológicas, psicológicas, y/o sociales a largo plazo, que puedan impedir su participación en igualdad de condiciones con los demás. Y tercero, inclusión para la persona con discapacidad es la posibilidad real de vivir con su familia, con una condición saludable y de bienestar, con educación y trabajo. Inclusión desde los otros ciudadanos es identificar, aceptar y adaptarse a la funcionalidad de los seres humanos, permitir la participación social de los otros de acuerdo a la funcionalidad individual.

El objetivo de esta investigación es, identificar y exponer el tratamiento jurídico que impulsa las políticas públicas para amparar e incluir a las personas con discapacidad desde una cultura de los Derechos Humanos, visibilizándolas, valorándolas y tratándolas como sujetos de derecho; a la par que, desde el quehacer político se fomente, se aplique y se difunda como praxis la responsabilidad compartida entre el individuo, la familia, la sociedad y el Estado.

La relevancia está en la exposición de cada realidad y en el análisis comparativo, que aportan al entendimiento de los derechos humanos de las personas con discapacidad; continuando con el análisis de la efectivización o no de los derechos, que llevan a identificar el estado del ejercicio jurídico de las dos naciones hermanas.

\section{DESARROLLO}

Los datos públicos actualizados acerca de la discapacidad son limitados, se carece de información e indicadores comparativos entre los países latinoamericanos, y sin estos la toma de decisiones y políticas públicas se tornan poco asertivas e irreales. Los datos inclusivos son recabados en los censos que se realizan cada década; debido a la necesidad planteada desde la Organización de las Naciones Unidas para sus países miembros. Una primera realidad es que, de "46 países" (FAO, 1997), número de países citados como latinoamericanos en documentos de las Naciones Unidas, solo "19 países latinoamericanos realizaron 
censos durante el 2000 sobre discapacidad, bajo una u otra definición" (CEPAL, 2011).

Una segunda realidad es que no todos los países firmaron el acuerdo en la Convención de las Naciones Unidas, tampoco se comprometieron al mismo tiempo en el cumplimiento de los derechos de las personas con discapacidad; Ecuador se incorporó en la década pasada el 3 de mayo del 2008, mientras que Venezuela lo hizo a inicios de esta década, el 24 de septiembre del 2013. Después de la convención, la gestión ecuatoriana se flexibiliza en adelante y datos estadísticos de importancia se empiezan a publicar en los medios de difusión autorizados, se comparte públicamente que "existe un total de 451.931 personas con discapacidad. En lo educativo y laboral, el CONADIS reporta que existen actualmente 20.615 estudiantes con discapacidad en el Ecuador, de los cuales un 58,51\% realiza un tipo de educación regular, mientras que el $41,39 \%$ restante hace estudios especializados" (CONADIS, 2018). No se evidencia datos estadísticos formales del resto de la estructura económica y superestructura de la sociedad en relación con personas con discapacidad (economía, mercado de trabajo, competencias y modelos de apoyo, capacitación y desarrollo, educación, salud, arte, deporte, etc).

En Ecuador lo controversial de la gestión para personas con discapacidad es que existe inversión y políticas públicas, y no se alcanza el escenario jurídico establecido, específicamente: en primera instancia existe un gobierno preocupado por la inclusión, que trabaja a través de sus instituciones como el Ministerio de Inclusión Económica y Social (MIES), Ministerio del Trabajo (MDT), y Consejo Nacional para la Igualdad de Discapacidades (CONADIS), grupos de apoyo que son el resto de instituciones públicas intervinientes, sociedad civil principalmente representada a través de las organizaciones sociales, personas con discapacidad y familias de personas con discapacidad; y leyes a favor de la inclusión sociolaboral principalmente la Ley Orgánica de Discapacidad y su reglamento. En segunda instancia existe una motivación intrínseca promedio por la existencia de la inclusión. En tercera instancia existe un modelo de gestión que mira los aciertos de los otros países, y que en la implementación debe cuidar identificar las diferencias del contexto extranjero respecto al nacional; un claro ejemplo es que, la ley exige a las organizaciones y/o instituciones "la contratación de personas con discapacidad en un $4 \%$ de la nómina y entre otros beneficios otorga la disminución del $150 \%$ adicional para el cálculo de la base imponible del impuesto a la renta respecto a las remuneraciones y beneficios sociales que se aportan al Instituto Ecuatoriano de Seguridad Social (IESS) de cada persona con discapacidad, sustituto, trabajadores con cónyuge o hijo con discapacidad y que se encuentren bajo su cuidado" (Asamblea Nacional, 2012); sin embargo, la ley no contempla una metodología nacional general menos aún específica de formación, selección de acuerdo a las habilidades, identificación de grados de autonomía en el trabajo, permanencia en el trabajo, adaptación sociolaboral.

La realidad ecuatoriana visibiliza un proceso parcial de inclusión sociolaboral en función del cumplimiento de parte de los factores, en otras palabras "puede variar dependiendo de varios factores: gravedad de la deficiencia subyacente, influencias y expectativas sociales, políticas y cultura, aspectos de entornos naturales y construidos, disponibilidad de tecnología y dispositivos de asistencia, apoyo y participación de la familia y la comunidad" (CDC, 2017). Lo que significa que, es necesario el aparataje gubernamental y resulta insuficiente, requiere políticas públicas especialmente sobre: educación a la ciudadanía en general y la asignación de recursos en forma persistente y controlada, desarrollo de una cultura sociolaboral 
inclusiva basada en resultados, en la que "la sociedad en su conjunto reconozca las necesidades y las contribuciones de las personas con discapacidad". (Comunidades Europeas, 2007)

En Venezuela lo controversial es que, debido a una democracia fragmentada con evidencias sociales, se producen movimientos migratorios inclusive de personas con discapacidad, especialmente hacia los países vecinos, como: Colombia, Ecuador, Perú, Brasil, y hacia otras zonas geográficas del mundo. Concluyentemente, "la democracia, el desarrollo social y económico son interdependientes y se refuerzan mutuamente" (OEA, 2001). La relevancia de poseer datos actualizados en un medio socioeconómico y político controlado, es una limitante en el país; situación que conlleva a la necesidad de procesos de inclusión social legal, en los países a los que los ciudadanos migran. Ecuador es un país elegido por los migrantes, sus leyes como la Ley Orgánica de Discapacidad (art 5, literal a) puntualiza al sujeto de derecho, como "las personas con discapacidad ecuatorianas o extranjeras que se encuentran en territorio ecuatoriano" (Asamblea Nacional, 2012) entre otros lineamientos, y les asigna los derechos sin excepción.

La revisión de textos constitucionales y leyes que, en Ecuador, y Venezuela consagran los derechos de las personas con discapacidad y su protección efectiva, se sitúa, integrando saberes y disciplinas, en el marco metodológico de la hermenéutica jurídica. La revisión se realiza a través del estudio de derecho comparado, el cual es definido por Ossorio como la "ciencia cuyo objeto es el estudio de las semejanzas y diferencias entre los ordenamientos jurídicos de dos o más países" (Ossorio, 2019). Igualmente, el estudio ha sido abordado desde una consideración politológica "al referir al Derecho como al Estado, como dos caras de una misma moneda" (Bobbio, 2006).

\section{I)Algunos estudios precedentes}

María Álava (2017) en su investigación: Actos jurídicos de los discapacitados intelectuales y la defensa de sus derechos como consumidores, analiza el marco jurídico ecuatoriano referido al derecho que tienen las personas con discapacidad intelectual, y del análisis realizado se descubre que existen vacíos, falencias que atentan contra estas personas, particularmente en lo que respecta a sus derechos como consumidores, "propone realizar algunas reformas puntuales en el ordenamiento jurídico, en lo que corresponde al establecimiento de una metodología que determine los diferentes grados de discapacidad" (Alava, 2017).

Los grados son marcados por la medicina para "diagnósticos clínicos" (Morrison, 2014) del DSM5, DSM6: médico, psiquiátrico, psicológico; en la práctica existe un desfase para que otras áreas de conocimiento ejecuten un trabajo más inclusivo; un ejemplo real, es el área empresarial, que para una verdadera inclusión requiere como mínimo la identificación de grados de: autonomía en el trabajo, permanencia en el trabajo, adaptación sociolaboral; estos son grados con mayor especificidad, puesto que están asociados con habilidades reales y comprobables para el trabajo.

Dávila, Naya y Lauzurika (2017) publicaron que más que la propia discapacidad son las barreras que surgen de la actitud y del propio entorno, las que obstaculizan plena y efectivamente cualquier posibilidad de inserción y participación social. El estudio hace una revisión y análisis de los Tratados Internacionales de Derechos Humanos, los que sin dudas protegen los derechos de las personas discapacitadas y su no discriminación, arribando a la conclusión de que tal protección no asegura la integración social de las mismas, dado que "reconocer un derecho no implica necesariamente el ejercicio práctico de éste" (Pauli Dávila, 2017). Para que haya efectivo goce de lo establecido en la norma legal, se requiere del diseño y puesta en 
práctica de políticas y estrategias que están bien específicas y que tengan el compromiso de generar cambios, transformaciones, en el mundo real, del día a día.

Juan Echeverría (2011) realizó una investigación en la Universidad Central de Venezuela, en Caracas, Venezuela, que se intitula Régimen jurídico de las personas con discapacidad. En dicho estudio específica y compara las regulaciones jurídicas existentes en Venezuela relacionadas con el régimen laboral aplicable en los casos de personas con discapacidad. Igualmente, con esta investigación se acometió un estudio comparativo entre las disposiciones jurídicas de El Salvador, Bolivia, México, Chile y Perú con el ordenamiento legal venezolano. La metodología empleada para realizar la investigación es la de tipo documental, de carácter descriptivo que abordó tanto la legislación, como la doctrina y la jurisprudencia venezolanas y las normas contenidas en las Declaraciones y Convenios internacionales relacionados con la materia. Concluye dicho estudio indicando que hay avances significativos en el campo jurídico y que como parte de la responsabilidad social se deben procurar múltiples opciones que impliquen la contratación de personas con discapacidad conforme a las potencialidades que tengan y a la capacitación que reciban.

Tapia y Tarco (2010) realizan un análisis de documentos desde el derecho comparado, "observan vacíos legales en el ordenamiento civil del Ecuador, concluyen en la generación de una amplia protección a las personas con discapacidad" (Tarco, 2010). Recomiendan dos situaciones: la primera realizar modificaciones al Código Civil a fines de incluir la protección por discapacidad, concordando con la Constitución y las leyes especiales; y la segunda, asegurar una adecuada capacitación y actualización de los profesionales del derecho en su proceso de formación sobre personas con discapacidad.

En la investigación sobre Derecho Comparado que considera algunos países de América como: Argentina, Uruguay, Colombia, Puerto Rico, México, los Estados Unidos de Norteamérica y Venezuela, el autor arriba a la conclusión de que las legislaciones estudiadas "promueven la protección de los discapacitados para que no sean discriminados en sus derechos, incluyendo las de inclusión laboral, tanto en empresas públicas como las privadas" (Rico, 2006). Se observa como la inclusión laboral tiene ya la atención de varios escenarios geográficos.

\section{II) Derechos constitucionales de las personas con discapacidad en Ecuador y Venezuela}

La Constitución de la República del Ecuador establece en el Preámbulo que el pueblo soberano del Ecuador decidió construir, entre otras cosas importantes "una nueva forma de convivencia ciudadana, en diversidad y armonía con la naturaleza, para alcanzar el buen vivir, el Sumak Kawsay" (Asamblea Nacional, 2008) y en un artículo puntualiza el principio de igualdad (11 literal 2) así: "todas las personas son iguales y gozarán de los mismos derechos, deberes y oportunidades" (Asamblea Nacional, 2008).

Del igual modo indica el referido Preámbulo que también se propone construir: una sociedad que respeta en todas sus dimensiones, la dignidad de las personas y sus colectividades.

La Constitución ecuatoriana prescribe en el Título I, Elementos Constitutivos del Estado, Capítulo primero, Principios fundamentales, Art. 1 que:

El Ecuador es un Estado constitucional de derechos y justicia, social y democrático, soberano, independiente, unitario, intercultural, plurinacional y laico. Se organiza en forma de república y se gobierna de manera descentralizada. 
Por otra parte, el numeral 1 del Art. 3, ejusdem (del mismo texto), señala que uno de los deberes primordiales del Estado es el de:

Garantizar sin discriminación alguna el efectivo goce de los derechos establecidos en la Constitución y en los instrumentos internacionales, en particular la educación, la salud, la alimentación, la seguridad social y el agua para sus habitantes.

Las obligaciones que asume el Estado ecuatoriano se orientan, en gran medida, al logro del sumak kawsay que, en definitiva, es el buen vivir; esto último es posible lograrlo siempre que, conforme lo establece la Carta Magna en el numeral 5 del precitado artículo 3, se acometa la planificación del desarrollo nacional, erradicando la pobreza, promoviendo el desarrollo sustentable y redistribuyendo los recursos y la riqueza. "Auspiciar la igualdad, la cohesión, la inclusión y la equidad social y territorial en la diversidad" (SENPLADES, 2013). Ello es posible concretarlo mediante el diseño y aplicación de políticas públicas adecuadas y racionales.

Es en orden al logro de tal propósito donde la educación juega un papel primordial; tanto es así que el Art. 26 constitucional señala que la misma es:

...un área prioritaria de la política pública y de la inversión estatal, garantía de la igualdad e inclusión social indispensable para el buen vivir.

De la lectura e interpretación del articulado de la Constitución ecuatoriana puede apreciarse que el constituyente incluyó, en el espíritu, propósito y razón de la norma suprema, el principio de "corresponsabilidad" o "responsabilidad compartida" al consagrar que en el logro o materialización de los derechos sociales, "las personas, las familias y la sociedad" tienen la responsabilidad de participar, con lo cual, junto al Estado, es posible darle concreción a los derechos y garantías establecidos en la Ley Suprema como lo es el texto constitucional.

Siguiendo con el análisis normativo que se lleva a cabo en este escrito, se observa que, en el Capítulo Tercero, referido a los Derechos de las personas y grupos de atención prioritaria, del Título II, se encuentra la Sección sexta, de las Personas con discapacidad. En dicha Sección de la Constitución ecuatoriana hay tres artículos, del 47 al 49, ambos inclusive, que norman todo lo concerniente a las personas con discapacidad; se hace referencia a la garantía de políticas de prevención, así como a la equiparación de oportunidades y a la integración social. A tal efecto, vuelve a referirse la acción conjunta y corresponsable del Estado, la sociedad y la familia, de manera, pues, que es un llamado a la acción ciudadana, junto a las instituciones privadas y con el sector público de manera democrática, mancomunada y solidaria, sin paternalismo.

En el elenco de enunciados garantistas para las personas con discapacidad, se puede apreciar el modo cómo estos se interrelacionan y la manera en que la educación en general y la especializada en particular se orienta (numerales 7 y 8 del precitado Art. 47 constitucional) al desarrollo de "potencialidades y habilidades para su integración y participación en igualdad de condiciones". El deber ser constitucional en materia educativa reconoce el derecho a una educación especializada para las personas con discapacidad intelectual, y de igual manera se procura el fomento de las capacidades mediante la creación de centros educativos y programas de formación específicos. Todo ello se complementa con una atención psicológica de carácter gratuito para la persona y la familia, cuando de discapacidad intelectual se trata.

En Ecuador existe la Ley Orgánica de Discapacidad en Ecuador (LOD), que contempla varias áreas y escenarios para la protección e inclusión de las personas, como: medidas de acciones afirmativas (art 17), acceso a los servicios de promoción, prevención, atención especializada permanente y prioritaria, habilitación 
y rehabilitación funcional e integral de salud (art 19), medicamentos, insumos, ayudas técnicas, producción, disponibilidad y distribución (art 23), seguro de vida y/o salud y medicina prepagada (art 25), derecho a la educación (art 27), inclusión étnica y cultural (art 36), derecho a la cultura (art 42), derecho al deporte (art 43), derecho al trabajo (art 45), políticas laborales (art 46), inclusión laboral (art 47), sustitutos (art 48), deducción por inclusión laboral (art 49), mecanismos de selección de empleo (art 50), estabilidad laboral (art 51), derecho a la vivienda (art 56), afiliación voluntaria (art 83), pensión por discapacidad permanente (art 84), jubilación especial por vejez (art 85). El Reglamento a la LOD, contempla información ampliada de los derechos y beneficios de las personas con discapacidad, además se encuentra determinado en la disposición transitoria primera que existe "un plazo de noventa (90) días a partir de la entrada en vigencia para expedir la normativa secundaria que garantice su efectivo cumplimiento" (Asamblea Constituyente , 2017).

Como puede apreciarse, el basamento constitucional que permite y apoya el desarrollo e implantación de adecuadas políticas públicas que propendan a la consolidación de instituciones y cultura democráticas (una forma ética y humana de biopolítica), inclusivas para las personas con discapacidad, existe, es claro, no admite demoras en su efectiva materialización.

Si la Carta Magna del Ecuador se compara con lo prescrito por la de la República Bolivariana de Venezuela, no resulta descabellado colegir que ambos textos normativos se inscriben en lo que doctrinariamente puede calificarse como constituciones de amplio contenido social, democráticas y garantistas de los Derechos Humanos Sociales, con especial referencia a las personas con discapacidades

A continuación, siguiendo con el desarrollo de este estudio de Derecho Comparado, se analiza lo que concierne a la Constitución vigente en Venezuela. Vale decir, en primer lugar, que el 15 de diciembre del año 1999, mediante referéndum popular se aprueba, en la ciudad de Caracas, capital de Venezuela, la Constitución discutida y debatida por la Asamblea Nacional Constituyente. Este "texto coloca énfasis en el aspecto social, lo cual constituye el rasgo más novedoso, así como lo concerniente al avance en materia de Derechos Humanos" (Garay, 2000). En tal sentido, comparte con el texto ecuatoriano esa característica de reconocimiento y garantía de tales derechos con particular referencia a los que corresponden a la sociedad en su conjunto.

La Constitución de la República Bolivariana de Venezuela, en su Preámbulo, al igual que la ecuatoriana, alude a los antecedentes históricos de la creación de la patria y al carácter multiétnico y pluricultural que tiene la República, refundada gracias al proceso político constituyente. En el artículo 2 se prescribe que:

Venezuela se constituye en un Estado democrático y social de Derecho y de Justicia, que propugna como valores superiores de su ordenamiento jurídico y de su actuación, la vida, la libertad, la justicia, la igualdad, la solidaridad, la democracia, la responsabilidad social y en general, la preeminencia de los derechos humanos, la ética y el pluralismo político.

En orden a dicha proclamación se desarrolla el resto del texto constitucional, y en el artículo 3 ejusdem se lee que son fines esenciales del Estado venezolano por tanto, sustantivos, "defender y desarrollar la persona así como respetar su dignidad, ejercer la democracia, construir una sociedad de justicia, que ame la paz, promueva la prosperidad y el bienestar del pueblo" (Asamblea Nacional Constituyente, 1999). En este sentido podría interpretarse que se alude a una idea de sociedad fundada 
en lo que en Ecuador han denominado el "buen vivir de los pueblos indígenas o Sumak Kawsay" (Houtart, 2011). En el mismo artículo 3, in fine, se consagra que "la educación y el trabajo son los procesos fundamentales para alcanzar dichos fines".

En el Título III, De los Deberes, Derechos Humanos y Garantías. Capítulo I, Disposiciones Generales, Art. 19, se consagra la protección de los derechos humanos y se indica que estos se rigen por el principio de progresividad y, por consiguiente, se caracterizan por ser irrenunciables, indivisibles e interdependientes y se garantizan a toda persona sin discriminación alguna.

En el Art. 21, numeral 2, se indica que la ley garantizará que la igualdad de los derechos sea "real y efectiva", motivo por el cual se adoptarán todas las medidas que favorezcan a las personas que puedan ser discriminadas, marginadas 0 vulnerables. Ahora bien, en el Capítulo V, del Título III in comento, se encuentran los Derechos Sociales y de las Familias, y el Art 81 establece que todas las personas con "discapacidad o necesidades especiales" tienen derecho al ejercicio pleno y autónomo de sus capacidades y a ser integrados en la familia y en la comunidad.

Respecto de ellas, las personas con discapacidad o necesidades especiales, se sostiene que, mediante la participación de las instituciones públicas, de las familias y de la sociedad se garantizará que se respete su dignidad humana, que se les equipare en oportunidades, se les otorguen condiciones laborales satisfactorias, así como también se promueva su formación, capacitación y el acceso al empleo acorde con sus condiciones, en un todo conforme a la ley.

La Constitución venezolana garantiza el derecho humano a la educación (Art. 102) y, por otra parte, prescribe que la ley respectiva garantizará, a las personas con necesidades especiales o discapacidad, atención "integral, de calidad, permanente y en igualdad de condiciones y oportunidades" en materia educativa. Cabe acotar que la educación en las instituciones públicas es gratuita hasta el pregrado universitario, incluido éste. La educación y el trabajo son valorados como el potencial necesario para desarrollar la creatividad de cada ser humano, así como el pleno ejercicio de su personalidad en una sociedad democrática que valora éticamente tales actividades.

En Venezuela, la Ley Para personas con Discapacidad establece que la persona con discapacidad tiene derecho a participar directamente como "ciudadanos y ciudadanas plenos de derechos" (Asamblea Nacional de Venezuela, 2007). En la ley se aprecia que tanto la sociedad como la familia deben participar solidariamente.

Asamblea Nacional de Venezuela, 2007, en el artículo 2 de la ley in comento se establece el deber de planificar, coordinar e integrar en las políticas públicas todo cuanto concierne a la discapacidad; para ello debe tenerse en cuenta la prevención, la promoción, la protección y el efectivo aseguramiento del disfrute de los derechos humanos de los discapacitados, así como el respeto por la igualdad de oportunidades, asegurar la inclusión y la integración social, garantizar el derecho al trabajo y las satisfactorias condiciones laborales. ... quedan comprendidas todas las personas nacionales o extranjeras, residentes legales o en tránsito.

Puede estimarse, sin temor a equívocos, que los textos constitucionales de Ecuador y Venezuela, en lo que a la parte dogmática corresponde, comparten fundamentos y principios garantizadores de los derechos humanos, incluidos los que conciernen a las personas con discapacidad. 
Tabla 1:

Principales Semejanzas en la legislación venezolana y ecuatoriana para personas con discapacidad

República del Ecuador

República Bolivariana de Venezuela

La Constitución, contempla protección a ecuatorianos en condición de discapacidad, garantiza los derechos.

La Constitución, contempla protección a venezolanos en condición de discapacidad, garantiza los derechos.

Ley Orgánica de Discapacidades en Ley para las Personas con Discapacidad en Ecuador vigente a partir del 25 de Venezuela vigente a partir del 05 de enero septiembre del 2012, puntualiza al sujeto de derecho, como las personas con discapacidad ecuatorianas o extranjeras que se encuentran en territorio ecuatoriano. Se puede observar que crea la ley después de cinco años de haber aceptado los lineamientos en la Convención.

La mencionada ley incorpora la planificación, coordinación e integración en las políticas públicas todo cuanto concierne a la discapacidad, asegurar la inclusión y la integración social, garantizar el derecho al trabajo y las satisfactorias condiciones laborales.

Adhesión formal a la Convención de las Naciones Unidas sobre los Derechos de las Personas con Discapacidad desde el 2007, para crear los mecanismos políticos y legales que eliminen las barreras.

La Convención tiene jerarquía constitucional, por la cual tiene primacía respecto al derecho interno.

Información estadística formal limitada, sin mecanismo de actualización permanente. de 2007, con carácter de ley especial donde quedan comprendidas todas las personas nacionales o extranjeras, residentes legales o en tránsito en el territorio venezolano.

La mencionada ley incorpora la planificación, coordinación e integración en las políticas públicas todo cuanto concierne a la discapacidad, asegurar la inclusión y la integración social, garantizar el derecho al trabajo y las satisfactorias condiciones laborales.

Ratifica su participación después de seis años de la Convención de las Naciones Unidas sobre los Derechos de las Personas con Discapacidad, lo hace desde el 2013, para crear los mecanismos políticos y legales que eliminen las barreras.

La Convención tiene jerarquía constitucional, por la cual tiene primacía respecto al derecho interno.

Información estadística formal limitada, sin mecanismo de actualización permanente.

Fuente: Elaboración propia.

Tabla 2:

Principales Diferencias en la legislación venezolana y ecuatoriana para personas con discapacidad

República del Ecuador

República Bolivariana de Venezuela

Decisiones y políticas públicas en función de la información existente.

Un Estado, gobierno y democracia resquebrajada, sin evidencia de cumplimiento de políticas públicas y/o determinación de decisiones a favor de personas con discapacidad

En Ecuador lo controversial de la gestión para personas con discapacidad es

En Venezuela lo controversial es que, debido a una democracia fragmentada, esto

1. un gobierno preocupado por la inclusión, equipos de trabajo gubernamentales: MIES, MDT y CONADIS, equipos de apoyo que son el resto de instituciones públicas intervinientes, sociedad civil, personas con discapacidad y familias de bajo evidencias sociales; se producen movimientos migratorios inclusive de personas con discapacidad, especialmente hacia los países vecinos, como: Colombia, Ecuador, Perú, Brasil, Argentina y hacia otras zonas geográficas del mundo. 
personas con discapacidad; y leyes a

favor.

2. iniciativa, motivación intrínseca para la

existencia de la inclusión.

3. un modelo de gestión

Sin embargo, la realidad ecuatoriana

evidencia una gestión que aún no se ajusta

al escenario jurídico, social y dinámico

establecido.

Fuente: Elaboración propia.

\section{METODOLOGÍA}

Los métodos utilizados en el desarrollo del artículo son:

Método de análisis tratado como derecho comparado, luego de leer y analizar los documentos se ha identificado coincidencias, diferencias en las constituciones y leyes de los países respecto a los derechos de personas con discapacidad, con el objeto de proponer algún o varios cambios legales, exponer información sencilla y concreta de la discapacidad.

Método deductivo, habiendo leído documentos generales como son las Constituciones respectivas, se ha revisado las leyes de cada realidad, las políticas establecidas y sus aplicaciones en calidad de evidencias o hechos de inclusión de cada país en cuestión. Es decir, el sentido de la gestión es, desde lo general a lo particular.

Método comparativo: permite contrastar dos realidades legales, con culturas semejantes. Se ha detallado en el documento escrito los puntos importantes de la identificación y gestión en la temática de discapacidad, primero de un país y luego de otro; además se presenta dos tablas a manera de comparación de las realidades de dos países latinoamericanos cercanos geográficamente y semejantes culturalmente.

\section{RESULTADOS Y DISCUSIÓN}

El Estado, en los dos países, reconoce la responsabilidad de regular los medios, formas y mecanismos necesarios que permitan garantizar el desarrollo total e integral de las personas con discapacidades, a objeto de que, de un modo pleno y autónomo, en conformidad con sus particularidades, puedan realmente disfrutar los derechos humanos, integrarse efectivamente a la vida familiar y social para que se concrete, sin cortapisa alguna, su condición de ciudadanos.

En las dos realidades se reconoce que, deben participar corresponsable y solidariamente tanto los individuos, la familia y la sociedad, como el Estado, con "igualdad, solidaridad, responsabilidad, justicia social, bien común, cooperación y bienestar social" (Echeverría, 2011).

La construcción de leyes y políticas públicas son necesarias en los países, así como las estrategias utilizadas para su implementación y control; son estas últimas las débiles en las realidades comparadas.

Las barreras que la sociedad impone a través de las actitudes, y del propio entorno, a las personas que a su parecer no están dentro del esquema general, son las que obstaculizan plena y efectivamente cualquier posibilidad de inclusión y participación social; por lo cual, el rediseño en tiempo real de una cultura inclusiva 
es tan importante para avanzar con el cumplimiento de los derechos de las personas con discapacidad, como lo es respirar.

No cabe duda que los textos constitucionales (ecuatoriano y venezolano), así como sus diversas normas legales, coinciden en el espíritu, propósito y razón de amparar a las personas con discapacidad, integrarlas a la vida ciudadana sin discriminaciones de ningún tipo y dentro del mayor respeto a su dignidad humana.

Existe la oportunidad de mejora en la puntualización de los grados y/o una correlación con los niveles identificados en el DSM5, la implementación de las políticas públicas y que dichas políticas se basen en datos actualizados. El censo del 2020 se convierte en una estrategia de actualización, que se sugiere sea construido con preguntas ambiciosas para gestionar la situación real de las personas con discapacidad.

Finalmente, en la gestión de inclusión laboral para personas con discapacidad, Ecuador y Venezuela necesitan un trabajo depurado en cuanto a la identificación de grados de autonomía en el trabajo, permanencia en el trabajo, adaptación sociolaboral; estos son grados con mayor especificidad, puesto que están asociados con habilidades reales y comprobables para el trabajo y la productividad.

\section{CONCLUSIONES}

Una cultura inclusiva es indispensable no puede seguir idealizada y en esto la organización de las Naciones Unidas es esencial, pues en conjunto con los países miembros, tienen el poder y los medios para diseñar y trabajar con modelos de gestión para culturas inclusivas según las áreas del mundo a la que pertenecen los países, de acuerdo a sus características socioeconómicas y culturales.

Los Estados venezolano como ecuatoriano a través de sus constituciones, leyes, políticas garantizan por escrito y de forma general, el compromiso para el desarrollo de las personas con discapacidad, el cumplimiento de los derechos humanos como ciudadanos, la integración efectiva a la vida familiar, laboral y social. Son las estrategias específicas (es decir el cómo se va hacer), las que no están planificadas a detalle, determinadas, verificadas, carecen de mecanismo de retroalimentación. Al no estar claras las estrategias, tampoco lo están las políticas públicas, los modelos de gestión y capacitación, la acción de los actores, el presupuesto por asignar, la manera y período para la toma de datos que a través de la estadística se convierten en información para la toma de decisiones asertivas. Es evidente que trabajar por las personas con discapacidad requiere mayor planificación, estrategias, planes y medidas de control.

Existe leyes útiles en los dos países, lamentablemente también existe una disociación entre la dirección y la gestión, la dirección pertenece a los grupos de poder del momento, que orientan su conducta hacia el enriquecimiento y la obtención de ventaja sobre los demás; mientras que la gestión para las personas con discapacidad como otras gestiones requeridas por las sociedades no se ejecutan. El gobierno es quien asigna los cargos en las instituciones de acuerdo a su interés, lo destructivo es que cada vez que cambian los políticos, la forma de hacer las cosas es decir las estrategias cambian, la asignación de recursos cambia, incluso la atención a los programas previamente invertidos cambia; esta lucha de poder, de partidos políticos causa casi siempre la pérdida de dinero obtenido de los impuestos de la población, el retroceso de acciones beneficiosas para la sociedad en general. 


\section{REFERENCIAS BIBLIOGRÁFICAS}

Alava, M. (2017). Actos jurídicos de los discapacitados intelectuales y la defensa de sus derechos como consumidores. Recuperado de http://repositorio.uees.edu.ec/bitstream/123456789/1948/1/PAPER\%20ACTOS\%20J UR\%C3\%8DDICOS\%20DE\%20LOS\%20DISCAPACITADOS\%20INTELECTUALES \%20Y\%20LA\%20DEFENSA\%20DE\%20SUS\%20DERECHOS\%20COMO\%20CONS UMIDORES.pdf

Asamblea Constituyente. (2017). Reglamento a la Ley Orgánica de Discapacidades. Recuperado de https://www.consejodiscapacidades.gob.ec/wpcontent/uploads/downloads/2017/11/Regalamento-lod-decre_-194.pdf

Asamblea Nacional. (2008). Constitución de la República del Ecuador. Recuperado de https://www.oas.org/juridico/mla/sp/ecu/sp_ecu-int-text-const.pdf; https://www.finanzas.gob.ec/constitucion-de-la-republica/

Asamblea Nacional. (2012). Ley Orgánica de Discapacidades. Recuperado de https://www.consejodiscapacidades.gob.ec/wpcontent/uploads/downloads/2014/02/ley_organica_discapacidades.pdf

Asamblea Nacional Constituyente. (1999). Constitución de la República Bolivariana de Venezuela. Recuperado de https://www.oas.org/dil/esp/constitucion_venezuela.pdf

Asamblea Nacional de Venezuela. (2007). Ley Para Las Personas con Discapacidad en Venezuela. Recuperado de http://www.sipi.siteal.iipe.unesco.org/normativas/656/gaceta-oficial-ndeg-385982007ley-para-las-personas-con-discapacidad

Bobbio, N. (2006). Diccionario de la Política. Recuperado de https://www.biblioteca.org.ar/libros/131821.pdf

CDC. (2017). Inclusión de personas con discapacidades. Recuperado de https://www.cdc.gov/ncbddd/spanish/disabilityandhealth/disability-inclusion.html

CEPAL. (2011). Serie Población y Desarrolo. Recuperado de https://repositorio.cepal.org/bitstream/handle/11362/7135/S1100074_es.pdf

Comunidades Europeas. (2007). Inclusión de las personas con discapacidad. Recuperado de http://feafesgalicia.org/img/documentacion/guias/Inclusion-de-las-personas-condiscapacidad.pdf

CONADIS. (2018). Consejo Nacional para Igualdad de Discapacidades. Recuperado de https://www.consejodiscapacidades.gob.ec/estadisticas-de-discapacidad/

Echeverría, J. R. (2011). Régimen Jurídico Laboral de las personas con discapacidad. Recuperado de http://repositoriocdpd.net:8080/bitstream/handle/123456789/315/Tes_EcheverriaJR_ RegimenJuridicoLaboral_2011.pdf?sequence=1

FAO. (1997). América Latina y el Caribe. Recuperado de http://www.fao.org/3/V8300S/v8300s0o.htm

Garay, J. (2000). La Nueva Constitución. Caracas: CIAFRË.

Houtart, F. (2011). América Latina en movimiento. Recuperado de https://www.alainet.org/es/active/47004

SPPAT. (2019). Requisitos para protección por discapacidad. Recuperado de https://www.protecciontransito.gob.ec/servicios/proteccion-por-discapacidad/

Morrison, J. (2014). DSM-5 Guia para el diagnóstico clínico. Recuperado de https://animasalud.files.wordpress.com/2009/02/dsm-5-guia-para-el-diagnosticoclinico.pdf

OEA. (2001). Carta Democrática Interamericana. Recuperado de https://translate.google.com/translate?hl=es-

419\&sl=en\&u=http://www.oas.org/en/\&prev=search 
ONU. (2001). La discapacidad y la estadística. Recuperado de https://www.un.org/development/desa/disabilities-es/la-discapacidad-y-laestadistica.html

ONU. (2014). Convención sobre los derechos de las personas con discapacidad. Recuperado de https://www.ohchr.org/Documents/Publications/CRPD_TrainingGuide_PTS19_sp.pdf

Ossorio, M. (2019). Diccionario de ciencias jurídicas y políticas. Recuperado de http://herrerapenaloza.com/images/biblioteca/Diccionario-de-Ciencias-JuridicasPoliticas-y-Sociales---Manuel-Ossorio.pdf

Pauli Dávila, L. N. (2017). Las personas con discapacidad, el derecho a la educación y la Convención sobre los derechos del Niño en América Latina. Recuperado de http://repositoriocdpd.net:8080/bitstream/handle/123456789/1973/Art_DavilaBalsera P_Personascondiscapacidad.pdf?sequence $=1$

Rico, O. (2006). Inserción de personas discapacitadas en el mercado laboral de conformidad con el ordenamiento jurídico venezolano. Recuperado de http://www.repositoriocdpd.net:8080/bitstream/handle/123456789/273/Tes_RicoO_In sercionMercadoLaboral_2006.pdf?sequence=1

SENPLADES. (2013). Objetivos Nacionales para el Buen Vivir. Recuperado de Buen Vivir Plan Nacional 2013-2017: http://www.buenvivir.gob.ec/objetivos-nacionales-para-elbuen-vivir

Tarco, W. T. (2010). La protección a los derechos de las personas con discapacidad en el ordenamiento jurídico civil ecuatoriano. Recuperado de http://repositoriocdpd.net:8080/bitstream/handle/123456789/438/Tes_TapiaVillegas WA_ProteccionDerechosPersonas_2010.pdf?sequence $=1$

Victoria, J. (2015). Hablemos de discapacidad y derechos humanos. Recuperado de http://www5.diputados.gob.mx/index.php/esl/content/download/121470/609263/file/DI SCAPACIDAD\%20Y\%20DERECHOS\%20HMANOS.pdf 